\title{
A elaboração de um artigo científico: subsídios à apropriação desse gênero textual
}

\author{
Juliana Gava B. Silva* \\ Maria Teresa Baptistella Ferrari Pereira** \\ Luzia Bueno***
}

\begin{abstract}
Resumo
Este artigo visa apresentar os resultados de uma pesquisa desenvolvida por membros do Grupo de Pesquisa Análise da Linguagem, Trabalho Educacional e suas Relações; Análise de Gêneros textuais (ALTER-AGE), no projeto institucional "Trabalho docente, letramento e gêneros textuais", com o objetivo de depreender características do artigo científico na área de Educação para apresentar um modelo didático desse gênero textual que possa ser utilizado em cursos de graduação ou pós-graduação a fim de preparar os alunos para a escrita desse gênero e os professores para o seu ensino. Para isso, foram selecionados dez artigos de revistas mais bem avaliadas pela WebQualis Educação da CAPES, publicados entre 2008 e 2013. Na análise desses artigos, assumiram-se os pressupostos de Bakhtin (2000), Bakhtin/Volochinov (2009), Bronckart (1999, 2006) e Dolz e Schneuwly (2004). Os resultados das análises permitem perceber que os artigos científicos constituem um gênero complexo, polifônico, cujo diálogo com os outros textos precisa ser dominado pelo articulista para que o texto esteja adequado para ser publicado.

Palavras-chave: artigo científico; gênero textual; letramento acadêmico; modelo didático.
\end{abstract}

\section{THE ELABORATION OF A SCIENTIFIC ARTICLE: Subsiding the appropriation of this textual genre}

\begin{abstract}
This article aims at presenting the results of a research carried out by the members of the Research Group ALTER-AGE (Language Analysis, Educational Work and their relations; Textual genre analysis) within the institutional project "Teaching labor, literacy and textual genres". The aforementioned research had the goal of inferring characteristics of the scientific article in the field of Education so that a didactic model of this text genre can be presented, used by both undergraduate and graduate courses and students are prepared to write them, as well as teachers to pass it on. For that purpose we have selected ten articles from the best ranked magazines in WebQualis Educação da CAPES evaluation. They all have been published from 2008 to 2013. In the analysis of these articles, we have considered the assumptions of Bakhtin (2000, 2009), Bakhtin and Volochinov (2009), Bronckart (1999, 2006) and Dolz and Schneuwly (2004). The results showed that scientific articles constitute a complex and polyphonic genre. In order to produce a text which is adequate for publishing, the dialogue between the genre in question and other texts needs to be fully apprehended by the writer.
\end{abstract}

Keywords: scientific article; textual genre; academic literacy; didactic model.

\section{Introdução}

O ingresso no curso de pós-graduação stricto sensu pressupõe a realização de uma pesquisa que se consolidará em uma dissertação ou tese. Todavia, espera-se que esses estudos sejam socializados e, sendo assim, a produção de artigos científicos torna-se uma alternativa de grande relevância para o autor e para a comunidade científica. Além disso, sabemos que publicar artigos acadêmicos envolve também políticas e aspectos financeiros diretamente relacionados à produtividade e avaliação de desempenho dos pesquisadores nas respectivas áreas de pesquisa.

A política que envolve a implantação e

*Endereço eletrônico: gava_juliana@ hotmail.com

** Endereço eletrônico: bferrari.materesa @ig.com.br

*** Endereço eletrônico: luzia_bueno@uol.com.br manutenção dos cursos de pós-graduação segue as exigências da CAPES ${ }^{1}$. Os cursos devem ser recomendados e reconhecidos por esse órgão de fomento que certifica quantitativamente os programas. Nessa avaliação, os cursos recebem conceitos que podem variar de 3 a 7 e um dos principais critérios que estabelecem esse conceito é a produção intelectual dos alunos pesquisadores assim como dos docentes que são duplamente avaliados (BARRICELLI, 2009).

Para fazer um bom artigo, pressupõe-se que anteriormente o enunciador tenha feito a leitura de vários textos do mesmo gênero, uma vez que escrever um artigo é diferente de produzir uma resenha, um resumo, um memorial acadêmico ou 
uma dissertação.

No entanto, embora o enunciador tenha feito muitas leituras, ainda se faz necessário destacar os elementos que compõem um artigo a fim de auxiliá-lo na produção adequada deste gênero.

Nesse momento, temos como objetivo conhecer as características de um artigo científico e apresentar um modelo didático desse gênero textual utilizado em cursos de pós-graduação. Para isso, usaremos, primeiramente, como aportes teóricos os trabalhos desenvolvidos no Interacionismo Sociodiscursivo e teremos como foco a nossa análise de dez artigos científicos de revistas mais bem classificadas pela WebQualis Educação.

Esses textos foram publicados entre 2008 e 2013, sendo seis deles aceitos nos últimos dois anos e oito divulgados em periódicos avaliados pela Qualis com estrato A1, ou seja, de maior repercussão no meio acadêmico.

Para abordar a problemática a que se refere o título do nosso texto, dividimos o nosso trabalho em cinco partes. Na primeira, apresentaremos os pressupostos teóricos que dão suporte a essa temática e o modelo de análise de textos. Na segunda, exporemos os objetivos e a metodologia utilizada. Na terceira, traremos as orientações que auxiliam os pesquisadores a escrever e publicar seus artigos, para isso, apresentaremos um modelo didático do artigo científico abordando, através de subitens, os elementos constituintes desse gênero textual interpretando alguns dados segundo o modelo de análise de Bronckart (1999). Na quarta, falaremos sobre algumas possibilidades de uso desse gênero textual. Finalizando o nosso trabalho, tecemos algumas considerações acerca do assunto.

\section{Pressupostos teóricos}

$\begin{array}{rcl}\text { Nesta } & \text { seção, } & \text { apresentaremos as } \\ \text { contribuições } & \text { de } & \text { Bakhtin (2000), }\end{array}$
Bakhtin/Volochinov (2009) sobre o conceito dos gêneros do discurso, sobre a importância do outro no processo de construção do conhecimento segundo Vigotski $(2001,2010)$ e finalizaremos com a proposta de Bronckart $(1999,2006)$ sobre modelo de análise de textos.

\section{Princípios para a produção de um artigo científico}

Iniciaremos essa seção partindo da concepção bakhtiniana todas as esferas das atividades humanas estão sempre relacionadas com a utilização da língua e de que "cada esfera elabora seus tipos relativamente estáveis de enunciados sendo isso que denominamos gêneros do discurso" (BAKHTIN, 2000, p.279).

Seguindo os pressupostos de Bakhtin (2000), "os gêneros do discurso são as correias de transmissão que levam da história da sociedade à história da língua" (ibid, p.285).

Segundo esse pesquisador, os gêneros usados em determinada época refletem o momento na vida social das pessoas. Assim, os artigos científicos produzidos atualmente carregam características específicas de nossa época, são gêneros marcados por um momento histórico e trazem marcas do autor da obra que "manifesta sua individualidade, sua visão de mundo, em cada um dos elementos estilísticos do desígnio que presidia à sua obra" (ibid, p.298).

No entanto, todo texto é produzido com uma finalidade, e esta pressupõe um leitor, dessa forma constatamos o papel do outro na construção do conhecimento. Neste aspecto, recorremos a Vigotski $(2001,2010)$ que destaca a importância da interação social para o desenvolvimento psíquico.

$O$ pesquisador atribuía às interações sociais o mérito de promover o desenvolvimento já que a aprendizagem se dá por meio de um diálogo constante entre o externo e o interno do indivíduo social proporcionando uma elevação do pensamento a níveis superiores de conhecimentos. Segundo Vigotski (2001, p. 148-149), "o desenvolvimento do pensamento e da linguagem depende dos instrumentos de pensamento e da experiência sociocultural da criança".

Vigostski (2001) discute essa elevação de pensamento no conceito de Zona Proximal de Desenvolvimento (ZPD) em que a colaboração do outro torna o indivíduo mais capaz de realizar tarefas, primeiramente com ajuda e, posteriormente, sozinho. Esse conceito transforma o desenvolvimento proximal em desenvolvimento real.

Considerando a questão dos gêneros e das relações interpessoais, refletimos sobre como isso ocorre entre o leitor e o escritor; sobre o assunto, Bakhtin (2000, p.290) esclarece que "[...] o ouvinte que recebe e compreende a significação (linguística) de um discurso adota simultaneamente, para com este discurso, uma atividade responsiva ativa; ele concorda ou discorda (total ou parcialmente), completa, adapta, apronta-se para executar, etc".

Nesta direção, Bakhtin (ibid) considera que todas as esferas da atividade humana estão sempre 
relacionadas com a utilização da língua. Assim, observamos que o gênero em questão, o artigo científico, encontra-se inserido na esfera acadêmica e um dos pré-requisitos para a produção desse gênero é o diálogo que ele mantém com textos anteriores. Nessa perspectiva, nenhum texto é novo, mas, reformulado a partir das interpretações pessoais do autor.

Qualquer nova produção de linguagem se inter-relaciona com textos que foram produzidos pelas gerações anteriores e que se acumularam em um subespaço dos "mundos de obras e de cultura" que podemos chamar, seguindo Bakhtin (1984), de intertexto (BRONCKART, 2006 p. 250).

Ao refletirmos sobre as dificuldades encontradas pelos iniciantes durante o processo de construção de um artigo e o fato de o mesmo ser reescrito diversas vezes até a versão final, nos apoiamos nos estudos de Bronckart (2006) que propõe um modelo de análise dos textos; segundo ele (ibid, p. 244), "todo agir se efetiva sobre o pano de fundo de atividades e de ações já feitas e geralmente já avaliadas por meio da linguagem". Assim, o pano de fundo do agir do articulista acadêmico são as ideias extraídas de outros textos científicos, são modelos de agir que orientam as condutas.

No entanto, toda palavra do discurso "[...] comporta duas faces. Ela é determinada tanto pelo fato de que procede de alguém, como pelo fato de que se dirige para alguém. Ela constitui justamente o produto da interação entre locutor e ouvinte" (BAKHTIN/ VOLOCHINOV, 2009, p.117). Segundo esse autor é a palavra que liga locutor e interlocutor Sendo Assim, ao produzir um artigo científico é imprescindível considerar quem será o leitor deste. Mas como considerar o leitor em um artigo? Agindo como seria o esperado em um bom artigo científico. E quais seriam as características desse agir por meio da linguagem? Para chegar até elas, nos apoiamos no modelo de análise de textos do Interacionismo Sociodiscursivo (doravante ISD) de Bronckart (19/99, 2006, 2008), que defende a importância da linguagem nas interações sociais e seu papel fundamental no desenvolvimento humano.

\section{Modelo de análise de textos}

Seguindo os pressupostos do ISD, denominaremos as formas variadas de "discursos" geradas pelas modalidades particulares de organização de signos de "gêneros de textos".

Assim, o modelo de análise de texto de Bronckart (1999) pressupõe dois níveis: contexto de produção e arquitetura interna. O primeiro nível se refere ao conjunto de representações sobre a produção de um texto que deve ser levado em consideração, pois exerce grande influência sobre a produção textual. Nesse contexto, deve ser considerado tanto o mundo físico e real do agente produtor quanto o mundo sociossubjetivo deste. $\mathrm{O}$ lugar e o papel social do produtor também são significativos, assim como o momento histórico da produção e a posição social do receptor. Todos esses fatores contribuem para formar "a imagem que o agente dá de si ao agir" (ibid, p.94).

A arquitetura interna é a forma de organização de um texto a serem considerados três aspectos superpostos. O primeiro é formado pelo conteúdo temático, que é o conjunto resumido de informações que serão apresentadas no texto. $\mathrm{O}$ segundo nível refere-se aos tipos de discurso, sendo eles: discurso interativo, discurso teórico, relato interativo e narração. E, o último diz respeito às sequências textuais, sendo elas: narrativa, descritiva, argumentativa, explicativa, dialogal e outras formas de planificação.

O conteúdo temático de um texto são as representações construídas pelo agente-produtor do texto: "trata-se de conhecimentos que variam em função da experiência e do nível de desenvolvimento do agente e que estão estocados e organizados em sua memória, previamente, antes do desencadear da ação de linguagem" (BRONCKART, 1999, p 97-98).

O segundo nível, o da arquitetura interna se refere a dois aspectos: os aspectos linguísticodiscursivos referentes às questões de linguagem do texto, são considerados, neste caso, os mecanismos de textualização, entre eles os conectivos que ligam as partes dos enunciados, a coesão nominal e a coesão verbal que norteiam a relação entre nomes, verbos e outros termos presentes no texto. $\mathrm{O}$ outro aspecto são os dos mecanismos enunciativos que dizem respeito às vozes assumidas no texto e às modalizações avaliativas que compõem o enunciado.

Muitos estudiosos retomam o modelo de Bronckart para fins didáticos e o reorganizam em três níveis, que são: a) contexto de produção; b) aspectos discursivos e c) aspectos linguísticosdiscursivos, conforme o quadro a seguir: 
QUADRO 1 - Da análise de textos ao trabalho didático com gêneros

\begin{tabular}{|c|c|c|}
\hline $\begin{array}{l}\text { Modelo de análise de } \\
\text { Bronckart }\end{array}$ & \multicolumn{2}{|c|}{ Adaptações para fins didáticos } \\
\hline Níveis de análise & $\begin{array}{l}\text { Modelo didático } \\
\text { de um gênero }\end{array}$ & $\begin{array}{c}\text { Capacidades de linguagem } \\
\text { a serem desenvolvidas }\end{array}$ \\
\hline I.Contexto de produção & Contexto de produção & Capacidade de ação \\
\hline II.Infraestrutura textual & Aspectos discursivos & Capacidade discursiva \\
\hline $\begin{array}{c}\text { III.Mecanismos de } \\
\text { textualização e enunciativos }\end{array}$ & $\begin{array}{c}\text { Aspectos } \\
\text { linguístico-discursivos }\end{array}$ & $\begin{array}{c}\text { Capacidade } \\
\text { linguístico-discursiva }\end{array}$ \\
\hline
\end{tabular}

[ Bronckart (1999) e Schneuwly \& Dolz (2004)]

Tais adaptações para fins didáticos podem ser vistas nos trabalhos dos professores pesquisadores suíços Joaquim Dolz e Bernard Schneuwly (2004), onde propõem que antes de levar o gênero para a sala de aula, é necessário fazer o seu modelo didático, ou seja, "trata-se de explicitar o conhecimento implícito do gênero, referindo-se aos saberes formulados, tanto no domínio da pesquisa científica quanto pelos profissionais especialistas" (p.69-70).

No entanto, há uma diversidade de subsídios que norteiam a elaboração desse modelo, que aqui serão sintetizados em três princípios de: legitimidade, pertinência e solidarização. O primeiro se remete aos estudos que já abordaram o gênero, o segundo trata da necessidade do conhecimento acerca do assunto e o último princípio visa destacar as informações relevantes a serem socializadas com os demais interessados pelo assunto.

Conforme esse aporte teórico, um modelo didático se caracteriza por ser uma síntese das características frequentes do gênero, elaborada com o objetivo de facilitar o entendimento do professor sobre o gênero e de oferecer a esse professor um instrumento de trabalho, explicitando as dimensões ensináveis do gênero e permitindo a elaboração de sequências didáticas.

O uso do modelo didático possibilita também o desenvolvimento das capacidades discursivas dos alunos necessárias à produção de textos dos diferentes gêneros. Essas capacidades estão relacionadas com o conhecimento que se tem da infraestrutura textual de cada texto, ou seja, do plano geral do conteúdo temático, os tipos de discursos e as eventuais sequências.

Neste artigo, visamos apresentar um modelo didático do gênero artigo científico a fim de que professores e alunos de pós-graduação stricto sensu, que muito provavelmente também são professores, possam ter subsídios para desenvolverem atividades para se apropriarem desse gênero.

Antes, porém, na próxima seção, iremos nos deter nos objetivos e na metodologia empregada para a investigação sobre o gênero textual artigo científico.

\section{Objetivos e metodologia}

A presente pesquisa buscou conhecer as características de um artigo científico, de forma a proporcionar aos estudantes de pós-graduação subsídios à elaboração de outros textos do mesmo gênero através da apropriação desse gênero textual. Selecionamos dez artigos científicos publicados em periódicos (revistas) on-line que foram avaliados pela Qualis ${ }^{2}$ das áreas de Educação e Letras/ Linguística com estratos 1 e 2 (A1 e A2), cujas características (ano de publicação, título do periódico, vinculação institucional do mesmo e estrato) serão apresentadas em ordem alfabética do título do periódico e na ordem crescente do estrato, conforme o quadro abaixo.

QUADRO 2 - Características gerais dos periódicos analisados

\begin{tabular}{|c|c|c|c|c|}
\hline Autoria $^{\mathbf{3}}$ & $\begin{array}{c}\text { Ano de } \\
\text { publicação }\end{array}$ & Título do Periódico & $\begin{array}{c}\text { Vinculação } \\
\text { institucional }\end{array}$ & Estrato \\
\hline MENEGASSI & 2013 & Alfa: Revista de Linguística & UNESP \\
\hline
\end{tabular}




\begin{tabular}{|c|c|c|c|c|}
\hline CAMPOS & 2011 & em Linguística Teórica e Aplicada & PUC-SP & \\
\hline $\begin{array}{l}\text { BORTONI- } \\
\text { RICARDO }\end{array}$ & 2008 & \multirow{4}{*}{ Linguagem em (Dis)curso } & \multirow{4}{*}{$\begin{array}{l}\text { Universidade do Sul de } \\
\text { Santa Catarina }\end{array}$} & A1 \\
\hline MACHADO & 2010 & & & \\
\hline EUZÉBIO & 2013 & & & \\
\hline ZAVAM & 2012 & & & \\
\hline TILIO & 2012 & $\begin{array}{l}\text { Revista Brasileira de Linguistica } \\
\text { Aplicada }\end{array}$ & $\begin{array}{l}\text { Faculdade de Letras da } \\
\text { UFMG }\end{array}$ & \\
\hline BIONDO & 2012 & Trabalhos em Linguística Aplicada & UNICAMP & \\
\hline $\begin{array}{l}\text { PAES DE } \\
\text { BARROS }\end{array}$ & 2012 & $\begin{array}{c}\text { Bakhtiniana: Revista de Estudos do } \\
\text { Discurso }\end{array}$ & PUC-SP & A2 \\
\hline CONTI & 2011 & $\begin{array}{l}\text { BOLEMA: Boletim de Educação } \\
\text { Matemática }\end{array}$ & UNESP & \\
\hline
\end{tabular}

A estratificação é realizada pela Qualis através da conferência da qualidade das produções nos periódicos científicos que passam por um processo de atualização anual, cujos indicativos variam entre $\mathrm{A} 1$, o mais bem classificado; $\mathrm{A} 2$; $\mathrm{B} 1$; B2; B3; B4; B5 e C, sendo este último com atributo zerado. Tais informações podem ser acessadas por qualquer usuário através do site WebQualis.

Para encontrar tais textos, pesquisamos no Scielo $^{4}$, no Google Acadêmico ${ }^{5}$ e no sistema de bibliotecas de várias universidades, também acessamos o Portal de Periódicos da CAPES que viabilizou a leitura desses artigos produzidos em instituições que atendem aos critérios da CAPES, que visam à melhoria da qualidade do ensino superior.

$\mathrm{Na}$ análise dos textos, apoiamo-nos no modelo do ISD e buscamos verificar o contexto de produção e os elementos da arquitetura interna. Ao analisarmos o contexto dos artigos, um primeiro ponto que nos chamou a atenção foi o fato de que o artigo deve adequar-se às prescrições das revistas, ou seja, o seu produtor não pode escolher livremente o tamanho ou algumas outras características formais de seu artigo.

A seguir, apresentaremos as características dos artigos, iniciando pelas prescrições que norteiam a sua produção.

\section{Do planejamento à escrita de um artigo científico: um modelo didático}

Nesta seção de análise, organizada em subitens, inicialmente apresentaremos as normas de publicação do artigo com base nas informações encontradas nos periódicos analisados e, além disso, trazemos outros dados que são pertinentes a essa fase que antecede a elaboração do texto. Na sequência traremos o conceito desse gênero textual. Posteriormente, em consonância com os pressupostos do ISD, destacaremos os elementos constituintes de cada artigo dando ênfase para: o contexto de produção, os aspectos discursivos e aspectos linguístico-discursivos em Bronckart (1999). E, ao final, faremos a relação com a ideia de gênero nas dimensões didáticas como objeto ensinável em Dolz e Schneuwly (2004) além da análise de artigos analisados.

\section{As normas de publicação do artigo}

As revistas trazem uma seção em que apresentam para o autor regras que ele deve seguir para produzir o seu artigo. Nessas regras, encontramos os temas possíveis de serem publicados em cada revista; o tamanho que pode ter o texto e o tipo de formatação esperada. Além disso, há também as normas de como o artigo será submetido: enviado por email, correio ou inserido diretamente na página da revista.

Encontra-se ainda entre as exigências a solicitação de que o artigo não contenha marcas que permitam identificar o seu autor, já que o texto será avaliado, geralmente, por duas pessoas: um parecerista interno, ou seja, pesquisador que pertença ao conselho editorial do periódico, e outro parecerista ad hoc, sendo este um pesquisador que não pertença ao conselho editorial do periódico. Esses pareceristas avaliam a qualidade do texto e sua adequação à revista; caso indiquem problemas 
graves, os artigos são recusados; se houver pontos que podem ser facilmente modificados, os artigos voltam aos seus autores para que procedam às modificações. Os artigos só são publicados quando revisados.

Além disso, esses periódicos são publicados com uma periodicidade quadrimestral ou semestral $\mathrm{e}$, na sua maioria, requerem que os autores realizem um cadastro eletrônico para o envio de trabalhos.

$\mathrm{O}$ atendimento às normas da revista é um primeiro e muito importante passo para se conseguir a publicação do artigo, logo tem que ser feita de modo a se verificar bem todas as suas minúcias.

\section{$O$ artigo científico em si}

$\mathrm{O}$ artigo se caracteriza como um gênero do discurso onde o locutor (especialista no assunto tratado) escreve para outros especialistas, pois, segundo Bakhtin/Volochinov (2009, p.72), “é indispensável que o locutor e o ouvinte pertençam à mesma comunidade linguística, a uma sociedade claramente organizada". Especificamente, o artigo científico trata-se de um gênero secundário, pois é elaborado em circunstâncias de uma comunicação mais complexa e relativamente evoluída, no caso, da comunicação científica.

$\mathrm{Na}$ universidade há diversos textos como inerentes a esse meio acadêmico. São eles, alguns gêneros escritos, como o fichamento, o resumo, a resenha. Outros dos gêneros orais, como o seminário, arguição na defesa de dissertações ou teses. Entre os primeiros, está o artigo científico, cuja produção por parte do aluno passou a ser, para muitos docentes, exigência para obtenção de nota ao final de uma disciplina. Sendo assim, acreditamos que é necessário oferecer subsídios para que os alunos gradativamente se apropriem desse gênero.

Tal aprendizado, a nosso ver, não acaba ao término do curso, pois a proposta é de que os recém-formados escrevam a partir das dissertações e de novas pesquisas.

A seguir, apresentaremos um conjunto de elementos que pode influenciar durante a organização de um artigo.

\section{O contexto de produção e o conteúdo temático}

No nível do contexto de produção, em resumo, nota-se a presença do:

a) Enunciador: conhecido como autor, nesse caso é especialista/ pesquisador que domina o conhecimento sobre determinado assunto cuja área de interesse é contemplada no periódico escolhido;

b) Destinatários: também conhecidos como leitores ou público da revista, são aqueles especialistas formados ou em processo de formação (mestrandos e/ ou doutorandos) que se interessam pelo tema/ assunto do texto;

c) Lugar social: meio acadêmico de onde surgem as ideias para a produção do artigo;

d) Objetivo: informar o destinatário sobre uma pesquisa empírica em andamento ou concluída, no intuito de convencê-lo sobre a relevância da análise e dos resultados;

e) Tempo e espaço: quando foi escrito e onde será publicado o texto a fim de atender as exigências das normas de publicação da revista. É comum o autor escrever alguns meses antes da publicação e ir fazendo ajustes no texto.

Quanto ao conteúdo temático, ou seja, o conjunto de informações explicitadas, notamos que para a ABNT (NBR 6022, 2003, p. 2), o artigo científico é "parte de uma publicação com autoria declarada, que apresenta e discute ideias, métodos, técnicas, processos e resultados nas diversas áreas de conhecimento", podendo ser um artigo de revisão ou original. Espera-se, de qualquer modo, que o tema tratado seja relevante para a área da qual o periódico faz parte.

\section{Aspectos discursivos}

Ao produzir um artigo científico, o locutor precisa estar atento à estrutura apropriada para esse gênero. Para tanto é imprescindível respeitar as normas editoriais da revista selecionada e aquelas que subjazem tal referencial. Por sua vez, “[...] o discurso escrito é de certa maneira parte integrante de uma discussão ideológica em grande escala: ele responde a alguma coisa, refuta, confirma, antecipa as respostas e objeções potenciais, procura apoio, etc" (BAKHTIN/ VOLOCHINOV, 2009, p.128).

Considerando a leitura e o mapeamento de dez artigos, observamos que as revistas seguem as normas da ABNT (2003, p.1) que "constituem prescrições", nas quais também iremos nos apoiar.

A arquitetura textual é composta por três partes gerais de apresentação: elementos prétextuais, textuais e pós-textuais. As especificidades desses elementos devem se adequar às normas da revista. Em síntese, o autor deve considerar isto:

a) elementos pré-textuais: são aqueles que antecedem o texto trazendo uma visão geral sobre o que o leitor irá encontrar. São constituidos por título 
(e subtítulo se houver), nome(s) do(s) autor (es), identificação da filiação institucional, identificação do programa de financiamento da pesquisa (se houver), e um endereço eletrônico para contato. Deve-se também apresentar resumo, cuja quantidade de palavras, deve corresponder às normas de publicação, além disso, faz-se necessário apresentar uma sequência de palavras-chave na língua do texto (cuja quantidade também é explicitada nessas normas).

Embora, na versão definitiva do artigo, esses elementos apareçam expressos logo no início do texto, a elaboração deles deve ocorrer depois da organização dos elementos textuais, uma vez que sintetizam com precisão aquilo com que o leitor irá se deparar ao longo do artigo. Sugere-se uma brainstorming (expressão inglesa que significa "tempestade cerebral"), durante a escrita do artigo registrando as ideias centrais para a posterior escolha do título e nome dos capítulos.

b) elementos textuais: são aqueles que expõem o percurso teórico-metodológico. Subdividem-se em: introdução (justificativa, problema, pressupostos, hipótese, objetivos e síntese apresentando as seções posteriores), desenvolvimento (aporte teórico, contextualização do objeto de pesquisa - a problemática - tecendo articulações com os pressupostos definidos, descrição sobre a metodologia utilizada, resultados alcançados e sua discussão) e para encerrar, as considerações finais (ou conclusão, fazendo uma retomada da discussão ancorando-se na teoria exposta).

c) elementos pós-textuais: [são aqueles] que complementam o artigo e são escritos conforme a necessidade e exigências das normas para a publicação. São constituídos de: título (e subtítulo, se houver) em língua estrangeira, resumo e sequência de palavras-chave em língua estrangeira, notas de rodapé, referências bibliográficas, glossário, anexo(s), data de entrega e informações complementares.

Além disso, o locutor precisa estar atento às exigências para a formatação do texto revisando o resumo, a quantidade de palavras e de laudas, a fonte, a margem, os espaçamentos e parágrafos, a paginação e os créditos aos autores das obras citadas.

A leitura dos artigos selecionados revela que a escrita desse texto acadêmico apresenta peculiaridades que exigem atenção do enunciador, tratando-se assim de uma minidissertação que busca analisar uma problemática social da atualidade.

Percebemos que a estrutura dos artigos, títulos e subtítulos apresenta variações e, apesar de seguir a sequência dos elementos textuais, a divisão e subdivisão dos capítulos é pessoal. Para auxiliar na elaboração de um novo artigo, apresentamos um quadro que sintetiza a arquitetura textual:

QUADRO 3 - Elementos estruturais do artigo

\begin{tabular}{|c|c|c|}
\hline Elementos pré-texuais & Elementos textuais & Elementos pós-textuais \\
\hline $\begin{array}{ll}\text { - } & \text { Título; } \\
\text { - } & \text { Autores; } \\
\text { - } & \text { Instituição; } \\
\text { - } & \text { Resumo. }\end{array}$ & $\begin{array}{ll}\text { - } & \text { Introdução; } \\
\text { - } & \text { Desenvolvimento; } \\
\text { - } & \text { Considerações finais. }\end{array}$ & $\begin{array}{ll}\text { - } & \text { Elementos pré-textuais } \\
\text { na segunda língua; } \\
\text { - } & \text { Notas de rodapé; } \\
\text { - } & \text { Referências } \\
\text { bibliográficas; } \\
\text { - }\end{array}$ \\
\hline
\end{tabular}

Sugerimos que durante a escrita seja dada atenção aos tempos verbais utilizados no gênero e à pessoa verbal. Nesse caso, verificamos nos artigos analisados o uso do tempo presente, verbos ou locução verbal no infinitivo para apresentar/ reiterar o(s) objetivo(s) da mesma ao longo do artigo e discurso na $1^{\mathrm{a}}$ pessoa do plural, mesmo quando uma única pessoa escreve, pressupondo que o enunciador está falando em nome de alguma instituição/ lugar social, está assumindo a mesma posição epistemológica que a de outros pesquisadores citados no artigo

E, por último, verificamos o predomínio de um discurso teórico, pois o autor se distancia da situação da ação da linguagem, e a presença da sequência argumentativa, conforme o modelo de Bronckart (1999). Através desse tipo de discurso são trazidas as vozes de estudiosos, documentos, dados estatísticos etc, que corroboram para a validade da pesquisa, nesse texto o autor abstém-se de fazer apontamentos subjetivos, trazer crenças pessoais ou emitir julgamentos de valor sobre o assunto. Sendo assim, é através da apresentação detalhada dos dados e da exposição da fundamentação teórica que busca-se convencer o leitor da pertinência e validade do estudo. 


\section{Aspectos linguístico-discursivos}

Nesse aspecto destacamos os mecanismos de textualização, que contribuem para o estabelecimento da coerência temática e que, articulados à linearidade do texto, explicitam, considerando o destinatário, as grandes articulações hierárquicas, lógicas e/ou temporais do texto (Bronckart, 1999).

Ao analisarmos a linguagem utilizada no corpus desta pesquisa e, considerando o modelo didático proposto por Dolz e Schneuwly (2004), verificamos que os textos apresentaram características semelhantes que dizem respeito aos mecanismos de textualização: a conexão, a coesão nominal e verbal das quais trataremos posteriormente. De acordo com Bronckart (1999, p. 268):

[...] os de coesão nominal explicitam as relações de dependências existentes entre argumentos que compartilham uma ou várias propriedades referenciais (ou entre os quais existe uma relação de coreferência). A marcação dessas relações é feita sintagmas nominais ou pronomes, organizados em série ou constituindo cadeias anafóricas.

A coesão nominal pode ser percebida por meio de duas funções: a função de introdução, que consiste em marcar uma unidade de significação, e a função de retomada, que consiste em reformular essa unidade no decorrer do texto. $\mathrm{Na}$ análise da escrita de um texto, podemos verificar a retomada do nome do autor em um artigo científico através do uso de anáforas que podem ser pronomes pessoais, relativos, demonstrativos e possessivos ou ainda sintagmas nominais. Como podemos identificar nos exemplos a seguir:

Exemplo 1:

Nesta seção, discutiremos a metáfora que Schneuwly (1994) construiu, segundo ele, a partir de sua leitura da noção de gêneros textuais bakhtiniana à luz da psicologia vigotskiniana [...] e buscaremos esclarecer a noção de instrumento (psicológico) que o autor utiliza" (MACHADO, 2010, p.622).

Exemplo 2:

"Entre as histórias contadas por Chimmanda [...]. Segundo a contadora de história [...]. Embora o relato da escritora" (BIONDO, 2012, p. 245).

Os mecanismos de conexão contribuem para marcar as articulações da progressão temática e explicitam as relações existentes entre diferentes níveis de organização de um texto, podendo exercer as funções de segmentação quando articula os diferentes tipos de discursos presentes em um texto; de demarcação ou balizamento quando marcam os pontos de articulação entre as frases de uma sequência argumentativa; de integração das frases sintáticas à estrutura que constitui a frase de uma sequência ou de outra forma de planificação; de ligação por justaposição ou coordenação. E, por último, de encaixamento por subordinação.

Podem ser considerados elementos de conexão as conjunções, os advérbios ou locuções adverbiais, grupos preposicionais, grupos nominais e segmentos de frases. Em suma, são os organizadores textuais que garantem a articulação das ideias caracterizando um único texto e não um amontoado de frases.

Alguns conectivos comumente utilizados no gênero artigo científicos são, entre outros:

QUADRO 4 - Relação de conectivos identificados nos artigos analisados no entanto - enfim - portanto - logo que - entretanto - mas - como - por isso - depois disso - para isso - apesar disso - porém - todavia - contudo - ao contrário de - então - desta forma - por conseguinte - em resumo - em suma - nesse contexto - desta forma - diante do exposto - conformeno caso

Esses conectivos contribuem para a coerência temática do texto garantindo "uma unidade comunicativa articulada a uma situação e destinada a ser compreendida e interpretada como tal por seus destinatários" (BRONCKART, 1999, p. 259).

Os mecanismos de coesão verbal garantem a organização temporal verbalizadas no texto, contribuem para a explicitação das relações de continuidade e é marcada pelas escolhas dos sintagmas verbais assim como de seus determinantes, ou seja, verbos auxiliares, flexões e tempos verbais.

Analisando os textos, listamos os verbos utilizados para indicar os diferentes atos do autor nos artigos. Alguns deles: 
QUADRO 5 - Verbos mais utilizados nos artigos

apontar - descrever - definir - elencar - enumerar - ressaltar - caracterizar - exemplificar - dar
exemplos - contrapor - confrontar - mostrar - observar - pontuar - assinalar - relatar - esclarecer
- discorrer - salientar - comentar - dialogar - recorrer - abordar - questionar - julgar - refletir -
concluir - opor - diferenciar

A coesão verbal contribui para "a explicitação das relações de continuidade, descontinuidade e/ou oposição existentes entre os elementos de significação expressos pelos sintagmas verbais" (BRONCKART, 1999, p. 273).

Ainda no aspecto linguístico discursivo, destacamos os mecanismos enunciativos que contribuem para a manutenção da coerência pragmática (ou interativa) de um texto, para o esclarecimento dos posicionamentos enunciativos, ou seja, quais são as instâncias formais que assumem o que é enunciado nos textos? Quais vozes? E ainda, quais as avaliações e julgamentos do que foi explicitado nos textos? São mecanismos enunciativos as vozes enunciativas e os elementos modalizadores.
Ressaltamos que essas vozes podem ser percebidas de forma "neutra" e geralmente põem em evidência o autor empírico do texto. Contudo, em muitos casos, pode pôr em cena uma ou várias "outras" vozes, que são, por isso, vozes infraordenadas em relação ao narrador ou ao expositor. São vozes secundárias representando as instâncias sociais ou mesmo personagens do discurso (BRONCKART, 1999, p.326).

Vejamos alguns trechos extraídos dos textos onde nota-se a distinção entre a voz do próprio autor do artigo e outras vozes (dos pesquisadores cujos estudos fundamentam a pesquisa, de instituições sociais ou de poderes públicos através da legislação):

\section{QUADRO 6 - Vozes presentes no gênero artigo científico}

\begin{tabular}{|c|c|}
\hline 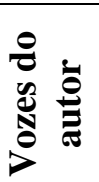 & $\begin{array}{l}\text { Como sabemos - a nosso ver - consideramos que - observamos nas -tomamos como - } \\
\text { nosso posicionamento científico nos leva a defender os - afirmamos a - salientamos, aqui, - } \\
\text { podemos constatar - podemos dizer que - vemos que - em nossas discussões, procuramos - } \\
\text { selecionamos - estabelecemos - concordamos com - em nossa compreensão - }\end{array}$ \\
\hline 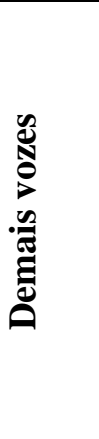 & $\begin{array}{l}\text { Defendida por autor* - autores (ano da obra) consideram que - autor (ano introduz a } \\
\text { questão do - de fato, segundo autor (ano), o - segundo apontam autores (ano) - para autor } \\
\text { (ano), é justamente a - o quadro teórico proposto por autor (ano) - autor (ano) caracteriza as } \\
\text { - o Programa..., que retratou- na perspectiva teórica da - o pesquisador francês autor (ano) } \\
\text { esclarece que - autor (ano) afirma - o autor propõe - autor explica que - o PNLD representa } \\
\text { - autor (ano) faz uma clara distinção entre - autor (ano) discute a - como se pode ler em - } \\
\text { autor faz menção a - autor (ano, página) chama a atenção para - da mesma maneira para } \\
\text { autores (ano) - por sua vez autores (ano, página) afirmam que - autor (ano, página), por sua } \\
\text { vez, valoriza o - essa percepção envolve os pressupostos discutidos por autor - autores } \\
\text { (ano) compreendem que - autor (ano) ressalta que - }\end{array}$ \\
\hline
\end{tabular}

As modalizações presentes em um texto são os diversos comentários, avaliações ou julgamentos que o autor faz a respeito do conteúdo temático apresentado pela voz enunciativa. Esses elementos modalizadores podem exercer diferentes funções, podendo ser:

- Lógicas, baseadas no mundo objetivo, como no exemplo: "Talvez, por esse motivo, em várias passagens do item sobre a concordância de palavras são apresentadas [...] outras possibilidades de concordância que não obedecem exatamente a essas regras de utilização da língua"(BIONDO, 2012, p. 255);

- Deônticas, baseadas nos valores do mundo social, como vemos no excerto: "Um projeto para implantação de mudança junto às universidades públicas e privadas foi desenvolvido, mas com muitas dificuldades a serem vencidas" (CAMPOS, 2011, p.221);

- Apreciativas, provenientes de uma avaliação precedente do mundo subjetivo, como vemos no trecho: "Considero grave 
um livro que apresenta tantas lacunas em relação à proposta" (TÍLIO, 2012, p. 1021);

- Pragmáticas, que explicita alguns aspectos da entidade (pessoa, personagem, grupo) responsável pela ação de linguagem, como no exemplo: "Bakhtin, quando emprega o termo transmitir, o faz para falar da transformação...” (ZAVAM, 2012, p. 253).

Vale ressaltar que os elementos modalizadores são fortemente presentes nas considerações finais dos artigos.

\section{Produção de um artigo científico: a construção de um modo de agir}

Com base nas leituras realizadas e de reflexões subsidiadas pelos pressupostos teóricos que adotamos, reconhecemos que a escrita dos primeiros artigos científicos irá exigir maior atenção do enunciador quanto à correspondência entre o conteúdo abordado, as normas e/ ou diretrizes para a publicação de artigos nos periódicos (revistas), a utilização das normas da ABNT e o uso da norma culta e das terminologias adequadas. Lembramos que o artigo possibilita um diálogo entre especialistas, ou seja, pessoas que se empenham no estudo aprofundado de uma temática, e dispõe de conhecimentos específicos sobre a mesma.

No decorrer das leituras dos artigos selecionados, notamos que os autores propõem uma discussão sobre uma realidade observada, como vemos a seguir:

Exemplo 3:

“(...) tomamos como objetivo deste artigo a apresentação e discussão de nossas hipóteses sobre essa relação (apresentada anteriormente pelas autoras) para, a seguir, advogarmos a necessidade de um programa de pesquisas que possam confirmálas" (MACHADO e LOUSADA, 2010, p.620).

$O$ uso desse gênero permite também o estabelecimento de relações entre os pressupostos teóricos utilizados e a busca de compreensão do emissor sobre o assunto propondo questionamentos aos destinatários, tais como:

Exemplo 4:

"Com base na afirmação da autora, perguntamos: como os gêneros multimodais são abordados na escola? Como se inserem no livro didático e que tratamento lhes é dado no principal material de acesso à leitura nas escolas públicas(...)"(PAES DE BARROS, 2012, p. 39).

Concordamos que os estudos em virtude da pesquisa e elaboração do artigo também suscitam reflexões no próprio enunciador:

Exemplo 5:

"Em nossa compreensão, essa dissonância sugere, sob vários aspectos, uma apropriação bastante parcial do ideário teórico que subjaz aos documentos oficiais e à literatura da área contemporaneamente; talvez não devamos falar em apropriação efetivamente, mas na repetição (...) tal como adverte Oliveira (2010)" (EUZÉBIO, 2013, p.31).

Além disso, a produção desse texto visa colaborar com a produção de conhecimentos, como podemos constatar:

Exemplo 6:

“(...) propõe-se um gesto de leitura analítico em um, gênero discursivo (...) procurando observar como esses conceitos permitem derivadas compreensões do texto escolhido, colaborando com os estudos sobre a complexa realidade da linguagem humana" (MENEGASSI, 2013, p.433).

Paralelamente, o leitor compartilha desses momentos de produção ao buscar os conhecimentos acerca do assunto em determinada área de pesquisa e quando utiliza os artigos para os estudos acerca da temática.

\section{Considerações finais}

Em nosso trabalho, tendo como pressuposto para análise do corpus o ISD, buscamos identificar as características de um artigo científico no intuito de apresentar um modelo didático do respectivo gênero textual.

Durante a pesquisa, procuramos destacar algumas especificidades que foram encontradas a partir da leitura dos dez textos selecionados: a produção do artigo científico é inerente às ações de pesquisadores, seja em virtude das prescrições da universidade ou de órgãos de fomento, o texto deve adequar-se às normas do periódico para submeter-se à avaliação na tentativa de uma publicação, o lugar social de onde surgem as ideias, a intencionalidade de informar e convencer o destinatário sobre a relevância da análise e resultados do estudo, as regras gerais de apresentação do texto etc.

Com base nessas similaridades, apresentamos um modelo didático que pode auxiliar tanto estudantes de graduação como os de pósgraduação a serem autores de artigos científicos e, além disso, preparar os professores para o ensino desse gênero acadêmico. No entanto, para que esses estudantes se inspirem e para que haja adequação ao 
mesmo, seria importante que se familiarizassem com a leitura de teses, dissertações e artigos científicos; em outras palavras, é preciso que o autor se aproprie dessa forma de socializar o conhecimento à sociedade, tanto quanto tenha o domínio sobre o assunto tratado, afinal, "[...] é indispensável que o locutor e o ouvinte pertençam à mesma comunidade linguística [...]" (BAKHTIN/VOLOCHINOV, 2009, p. 72).

Ao produzir um texto, o autor necessita dispor de certo conhecimento do gênero e dos tipos em uso na atualidade, pois estes se constituem em modelos que servem de inspiração para a elaboração do próprio artigo científico. Vale ressaltar a importância da representação que o autor tem da situação em que se encontra, das decisões sobre a forma de abordar o assunto e dos conhecimentos linguísticos que dispõe resultando na construção de um estilo próprio de escrita.

Diante disso, o modelo didático proposto é constituído por uma série de elementos que são pertinentes ao momento em que foram produzidos e que foram identificados como semelhantes durante a análise dos artigos, todavia estes elementos são estáveis, pois estão em consonância ao contexto de produção, que é passível de modificações.

Acreditamos que nossa pesquisa possa motivar a escrita de novos artigos, já que oferece uma prescrição que norteia a construção desse texto acadêmico para diversos periódicos (revistas) na área de Educação. Por outro lado, pode suscitar a reflexão e subsidiar o planejamento de professores, no sentido de que eles também esclareçam as dúvidas dos pesquisadores iniciantes a respeito da divulgação de seus estudos e, além disso, incentivem a disseminação da produção científica.

Sendo assim, o estudante será (in) formado sobre qual direção caminhar para o seu aperfeiçoamento acadêmico e pessoal, assim como para a divulgação de conhecimentos científicos.

\section{Notas}

1 Coordenação de Aperfeiçoamento de Pessoal de

Nível Superior. Disponível no site:

http://www.capes.gov.br/.

2 "Conjunto de procedimentos utilizados pela Capes para estratificação da qualidade da produção intelectual dos programas de pósgraduação". Disponibilizado em: http://qualis.capes.gov.br/webqualis/principal.sea m. Acessado em 20 out. 2013.

3 Essa coluna corresponde ao primeiro autor do artigo, pelo qual será identificado no decorrer deste trabalho, o nome dos outros autores e as demais informações constam nas referências bibliográficas.

4 Pode ser acessado pelo endereço: http://www.scielo.org/cgi-bin/wxis.exe/applicati ons/scielo-org/iah/?IsisScript=iah/iah.xis\&b ase $=$ article \%5Edart.org\&nextAction $=$ lnk\&lang $=\mathrm{p} \&$ ind exSearch=\&exprSearch=ARTIGOS\%20CIENTIF ICOS

5 Pode ser acessado pelo endereço: http://scholar.google.com.br/

\section{Referências}

ALFA: Revista de Linguística (UNESP, Online). ISSN 1981-5794. Diretrizes para autores. http://seer.fclar.unesp.br/alfa/about/submissions\#aut horGuidelines. Acesso em 19 out. 2013;

ASSOCIAÇÃO BRASILEIRA DE NORMAS TÉCNICAS. NBR6022. Informação e documentação: artigo em publicação periódica científica impressa: apresentação. Rio de Janeiro, 2003;

BAKTHIN, M. A estética da criação verbal. São Paulo: Martins Fontes, 2000;

BAKHTHIN/VOLOCHINOV.1929. Marxismo e filosofia da linguagem. São Paulo: Editora Hucitec, 2009. $13^{a}$ edição;

BARRICELLI, E. Uma reflexão sobre a elaboração de artigos acadêmicos: o autor como trabalhador. Revista L@elem (Dis)curso. Vol 1. 2009;

BIONDO, Fabiana Poças. As diferentes versões de uma história única: a polêmica a respeito do livro didático por uma vida melhor e os estudos do(s) letramento(s). Trab. linguist. apl. [online]. 2012, vol.51, n.1, pp. 245-260. ISSN 0103-1813. Disponível em: <http://dx.doi.org/10.1590/S010318132012000100013>. Acesso em: 19 out. 2013;

BORTONI-RICARDO, S.. A leitura de livros didáticos: uma situação negligenciada. Linguagem em (Dis)curso, Local de publicação (editar no plugin de tradução o arquivo da citação $\mathrm{ABNT}$ ), 8, out. 2010. Disponível em: <http://www.portaldeperiodicos.unisul.br/index.php 
/Linguagem_Discurso/article/view/403/423>.

Acesso em : 19 out. 2013;

BRONCKART, J.P. Atividade de linguagem, textos e discursos: por um interacionismo sociodiscursivo. São Paulo: EDUC, 1999;

Atividade de linguagem, discurso

e desenvolvimento humano. Campinas: Mercado de Letras, 2006;

O agir nos discursos: das concepções teóricas às concepções dos trabalhadores. Campinas: Mercado de Letras, 2008.

CAMPOS, Maria Inês Batista. Textos argumentativos em materiais didáticos: que proposta seguir?. DELTA [online]. 2011, vol.27, n.2, pp. 219-234. ISSN 0102-4450. http://dx.doi.org/10.1590/S0102-

44502011000200002. Acesso em: 19 out. 2013;

CONTI, Keli Cristina; CARVALHO, Dione Lucchesi. O letramento presente na construção de tabelas por alunos da educação de jovens e adultos. Revista Bolema: Boletim de Educação Matemática-Vol.24, n. 40, dez. de 2011. ISSN 103636X. pp. 637-658 Acesso em: 19 out. 2013.

DOLZ, Joaquim; SCHNEUWLY, Bernard (orgs.). Gêneros orais e escritos na escola. Tradução e organização: Roxane Rojo e Glaís Sales Cordeiro. Campinas, SP: Mercado de Letras, 2004. 278 p. (Coleção as faces da linguiística aplicada);

EUZEBIO, Michelle Donizeth and CERUTTIRIZZATTI, Mary Elizabeth. Usos sociais da escrita: um estudo sobre práticas e eventos de letramento na vivência de professoras alfabetizadoras. Ling. (dis)curso [online]. 2013, vol.13, n.1, pp. 13-34. ISSN 1518-7632. http://dx.doi.org/10.1590/S1518-76322013000 10 0002. Acessado em: 19 out. 2013;

MACHADO, Anna Rachel and LOUSADA, Eliane Gouvêa. A apropriação de gêneros textuais pelo professor: em direção ao desenvolvimento pessoal e à evolução do "métier". Ling. (dis)curso (Impr.) [online]. 2010, vol.10, n.3, pp. 619-633. ISSN 15187632. http://dx.doi.org/10.1590/S151876322010000300009. Acesso em: 19 out. 2013;

MACHADO, Anna Rachel. LOUSADA, Eliane Gouvêa. TARDELLI Lília S. A.- Resumo In : Leitura e Produção de textos técnicos e acadêmicos. Parábola Editorial, 2004. São Paulo;

MENEGASSI, Renilson José; CAVALCANTI, Rosilene da Silva de M. Conceitos Axiológicos Bakhtinianos em propaganda impressa. Alfa: Revista de Linguística (UNESP. Online) v 57, n. 2, 2013. ISSN 1981-5794 (ON-LINE) http://seer.fclar.unesp.br/alfa/article/view/5133.

Acesso em: 19 out. 2013;

PAES DE BARROS, Cláudia Graziano and COSTA, Elizangela Patrícia Moreira da. Os gêneros multimodais em livros didáticos: formação para o letramento visual?. Bakhtiniana, Rev. Estud. Discurso [online]. 2012, vol.7, n.2, pp. 38-56. ISSN 2176-4573. http://dx.doi.org/10.1590/S2176-4573201200 020 0004. Acesso em: 19 out. 2013;

TILIO, Rogério. Atividades: PCN, letramento crítico e o panorama atual. Rev. bras. linguist. apl. [online]. de leitura em livros didáticos de inglês 2012, vol.12, n.4, pp. 997-1025. Epub 18-Set-2012. ISSN 1984-6398. http://dx.doi.org/10.1590/S198463982012005000010.Acesso em: 19 out. 2013;

VIGOTSKI, L.S.1934. A construção do pensamento e da linguagem. Tradução Paulo Bezerra. São Paulo: Martins Fontes. 2001;

, L.S..1930. A formação social da mente. São Paulo: Martins Fontes. 2010;

ZAVAM, Aurea. Transmutação: criação e inovação nos gêneros do discurso. Ling. (dis)curso [online]. 2012, vol.12, n.1, pp. 251-271. ISSN 15187632. http://dx.doi.org/10.1590/S151876322012000100012. Acesso em: 1 out. 2013.

\section{Sobre as autoras:}

Juliana Gava B. Silva: Professora do Ensino Fundamental I e II da Rede Municipal de Itatiba. Mestranda em Educação pela Universidade São Francisco. Itatiba. 
Maria Teresa Baptistella Ferrari Pereira: Professora da Educação Infantil da Prefeitura Municipal de Campinas. Mestranda em Educação pela Universidade São Francisco. Itatiba.

Luzia Bueno: Professora do Programa de Pós-graduação da Universidade São Francisco, doutora em Linguística Aplicada e orientadora de mestrado das demais autoras.

Artigo recebido em novembro de 2013

Artigo aprovado em fevereiro de 2014 